\title{
Antimicrobial Effects of Thymoquinone on Entamoeba histolytica and Giardia Iamblia
}

\author{
Bassem Yousef Sheikh', Manal Mohamed Elhassan Taha ${ }^{2}$, Waleed Syaed Koko ${ }^{3}$, and Siddig Ibrahim Abdelwahab ${ }^{3 *}$ \\ 'Al-Moalim MA Bin Ladin (MABL) chair for Scientific Miracles of Prophetic Medicine, College of Medicine, Taibah University, SAUDI ARABIA. \\ ${ }^{2} U$ nit of Biomedical Research, Medical Research Centre, Jazan University, P.O. Box 114 Jazan, Jazan 45142, SAUDI ARABIA. \\ ${ }^{3}$ Department of Microbiology, Medicinal and Aromatic Research Institute, National Research Centre, Khartoum, SAUDI ARABIA. \\ ${ }^{4}$ Unit of Biomedical Research, Substance Abuse Research Centre, Jazan University, P.O. Box 114 Jazan, Jazan 45142, SAUDI ARABIA.
}

\begin{abstract}
Background: Parasitic infections are a major difficulty in tropical and subtropical countries. Traditionally medicinal plants have been used in folk medicine to treat parasitic infections and are a valuable source of novel anti-parasitics. Objective: In our search for therapeutic alternatives to anti-protozoal chemotherapy, thymoquinone, the active ingredient of Black cumin (Nigella sativa) was examined. Materials and Methods: Thymoquinone was tested against Entamoeba histolytica and Giardia lamblia using in vitro susceptibility assays and the mortality of the parasites were then obtained using the standard calculations. The compound was also tested for 48 and 72 hours on both parasites. Results: The current study indicate that the mortality of TQ showed $85.5 \%, 91.5 \%$ and $96.8 \%$ mortality on $E$. histolytica for $25 \mathrm{ppm}$ at $24 \mathrm{hr}, 48$ and $72 \mathrm{hr}$, respectively, with $I \mathrm{C}_{50} 2 \times 10^{-19}$,. On the other hand, this natural compound showed a mortality of $82.83 \%$, $91.76 \%$ and $96.62 \%$ mortality on G. lamblia for 25 ppm at $24 \mathrm{hr}, 48$ and $72 \mathrm{hr}$, respectively, with $\mathrm{IC}_{50} 4.8 \times 10^{-5}$. Metrondizole powder gave $70.9 \%$
\end{abstract}

mortality at $156 \mathrm{ppm}$ at the same times. Conclusion: The current results indicate that TQ is more potent on E. histolytica compared to G. lamblia. Further pharmacological studies were needed to help in the clinical presentation of thymoquinone.

Key words: Prophetic Medicine, Nigella sativa, Thymoquinone, Entamoeba histolytica, Giardia lamblia.

Correspondence:

Dr. Siddig Ibrahim Abdelwahab, Department of Microbiology, Medicinal and Aromatic Research Institute, National Research Centre, Khartoum, SAUDI ARABIA.

Phone no: 00966173182881

Email: siddigroa@yahoo.com

DOI : 10.5530/pj.2016.2.12

\section{INTRODUCTION}

Protozoa are one of the three chief types of parasites that lead to diseases in humans. Protozoan Infections are contagious and can be transmitted via the fecal-oral route. ${ }^{1,2}$ Blood protozoa can be transmitted through a third source such as insects. ${ }^{3}$ There are four main groups of protozoa according to how they move. That includes the sarcodina (ameba), mastigophora (flagellates), ciliophora (ciliates) and the Sporozoa. ${ }^{4,5}$ Many parasitic diseases are known to clinicians and public health professionals, which includes trichomoniasis, babesiosis, malaria, toxoplasmosis, leishmaniasis, african sleeping sickness, giardiasis and amoebiasis. ${ }^{6}$ Giardiasis is transmitted through oral contact and caused by Giardia lamblia and known as intestinal protozoan diseases. ${ }^{7}$ Amoebiasis is caused by sarcodina group of protozoa (Such as Entamoeba histolytica) that invade body tissues. ${ }^{8,9}$

The ailments triggered by protozoan parasite are accountable for substantial mortality and morbidity, distressing more than 500 million of the world population. The epidemiological management of protozoan is insufficient due to complicatedness of vector and reservoir control; while the progress in the development of protozoan vaccine is slow and arduous. Currently, the chemotherapy stays necessary constituent of both clinical management and disease control programmer in prevalent areas. The medications in utilization as anti-protozoan agents were discovered over 60 years and number of issues limit their usefulness such as: high cost, drug resistance, poor compliance, low effectiveness and deprived safety. Recently, the searches for new drugs against protozoa parasite have been increased and more interest has been put on the traditional medicine, especially herbal remedies. ${ }^{10,11}$

Seeds' oil of Nigella sativa (Ranunculaceae), is widely used as a food and cure. ${ }^{12,13}$ Experimental studies confirmed that the plant is respiratory stimulant, diuretic, hypoglycemic, anti-inflammatory, antioxidant, anticancer, antimicrobial and analgesic. Previous phytochemical reports showed that the seed contain alkaloids, tannins, steroids and flavonoids. ${ }^{13-15}$ Thymoquinone (TQ), an active ingredient of Nigella sativa, has been reported to exhibit anti-oxidant, anti-inflammatory, antimcrobial and anti-tumor activities. The current study was designed to assess the Effects of thymoquinone on Entamoeba histolytica and Giardia lamblia.

\section{MATERIALS AND METHODS}

\section{Parasite isolate}

Entamoeba histolytica and Gardia lambelia used in all experiments were taken from patient. All positive samples were examined by wet mount preparation. Trophozoites of the two parasites were performed at $37 \pm$ $1^{\circ} \mathrm{C}$ in RPMI 1640 medium containing 5\% of bovine serum. The trophozoites were maintained for the assays and were employed in the log phase of growth. Parasites were counted under the microscope by haemocytometer chamber.

\section{In vitro susceptibility assays}

In vitro susceptibility assays of the current research used the sub-culture method. ${ }^{16}$ This is highly stringent and sensitive method for assessing the anti-protozoal effects (gold standard) particularly in Entamoba histolytica, Gairdia intestinalis and T. vaginalis. Five $\mathrm{mg}$ from the compound was dissolved in $5 \%$ dimethyl sulfoxzide (5000 ppm). The concentrates were stored at $-20^{\circ} \mathrm{C}$ for further analysis. Sterile 96 -well microtite plate was used for test material, positive control and negative control. The final volume in the wells was $100 \mu \mathrm{l}$.

Each test included metronidazole pure compound [(1-(2-hydroxyethl)2-methyl-5 nitroimidazole], a drug was used as positive control in concentration $312.5 \mu \mathrm{g} / \mu \mathrm{ml}$, whereas untreated cells were used as a negative controls (culture medium plus trophozoites). Samples were taken for counting at $0,24,48,72,96$, and 120 hours. For counting, the samples 


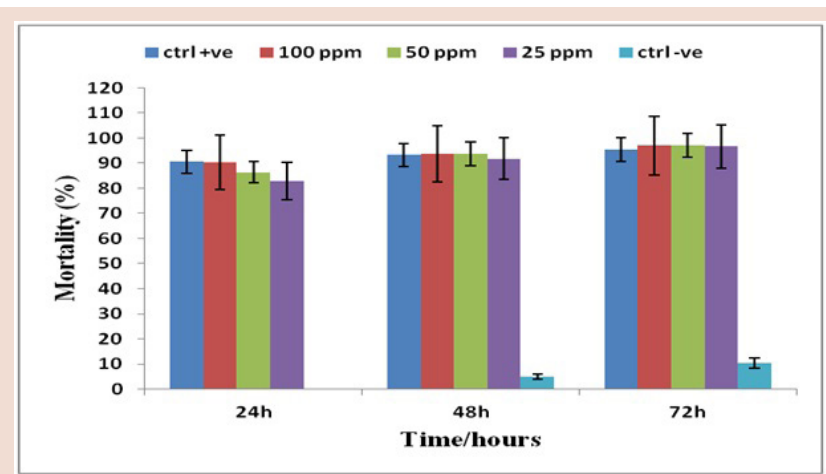

Figure 1: In vitro activity of Thymoquinone against Giardia lambelia; mortality percentage in relation to time

were mixed with Trypan blue in equal volumes The final number of parasites was determined with haemocytometer in triplicate. The mortality $\%$ of parasite for each extract activity was carried out according to the following formula:

\section{Mortality of parasite $(\%)=$}

Control negative-tested sample with extract $\times 100$

$$
\text { Control negative }
$$

\section{Statistical analysis}

All data were presented as means \pm S.D. Statistical analysis for all the assays results were done using Microsoft excel program. Student t test was used to determine significant difference between control and plant extracts at level of $P<0.05$.

\section{RESULTS AND DISCUSSION}

Medicinal chemists have discovered an amount of medications which can be utilized against numerous but by far not all endoparasites. A main difficulty is that many of these drugs were synthesized many years ago and some parasites have become resistant to them. The development of novel antiparasitic medications has not been much of precedence for the pharmaceutical industry because many of the parasitic diseases happen in deprived countries where the populations cannot give to pay a elevated price for the drugs. Thus an investment in drug progress against parasitic diseases is a hazardous matter. An alternative to synthetic drugs is the search for anti-parasitic plant extracts or secondary metabolites derived from them. ${ }^{17-19}$ The current study was designed to assess the Effects of thymoquinone on Entamoeba histolytica and Giardia lamblia.

Seeds' oil of Nigella sativa (Ranunculaceae), is widely used as a food and cure. ${ }^{12,13}$ Experimental studies confirmed that the plant is respiratory stimulant, diuretic, hypoglycemic, anti-inflammatory, antioxidant, anticancer, antimicrobial and analgesic. Previous phytochemical reports showed that the seed contain alkaloids, tannins, steroids and flavonoids. ${ }^{13-15}$ Thymoquinone (TQ), an active ingredient of Nigella sativa, has been reported to exhibit anti-oxidant, anti-inflammatory, antimcrobial and anti-tumor activities.

Thymoquinone was tested on both Entamoeba histolytica and Giardia lamblia using the range of concentrations $0-200 \mu \mathrm{g} / \mathrm{mL}$. Figure 1 indicates that the mortality of TQ showed $85.5 \%, 91.5 \%$ and $96.8 \%$ mortality on E. histolytica for $25 \mathrm{ppm}$ at $24 \mathrm{hr}, 48$ and $72 \mathrm{hr}$, respectively, with $\mathrm{IC}_{50}$ $2 \times 10^{-19}$, On the other hand, this natural compound showed a mortality of $82.83 \%, 91.76 \%$ and $96.62 \%$ mortality on G. lamblia for 25 ppm at 24 $\mathrm{hr}, 48$ and $72 \mathrm{hr}$, respectively, with $\mathrm{IC}_{50} 4.8 \times 10^{-5}$ as shown in Figure 2. The compound was also tested for 48 and 72 hours on both parasites.

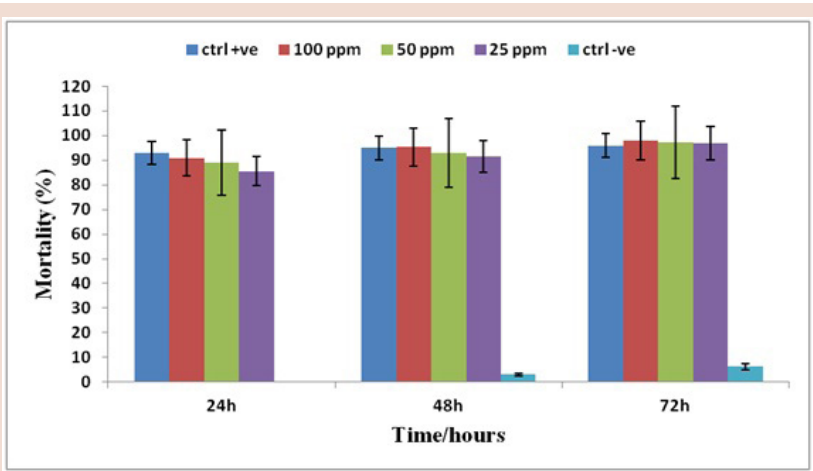

Figure 2: In vitro activity of Thymoquinone against Entamoeba histolytica; mortality percentage in relation to time

The current results indicate that TQ is more potent on E. histolytica compared to G. lamblia. Metrondizole powder gave $70.9 \%$ mortality at 156 ppm at the same times.

$N$. sativa seeds were found to turn render the parasite susceptible to damage by the host and may play a role in the anti-schistosomal potency. The oil prevented most of the hematological and biochemical alterations and noticeably enhanced the antioxidant capability of schistosomiasis mice contrasted to the infected untreated ones. ${ }^{20-22}$ Dietary intake of chloroquine with $N$. sativa was examined previously and found effective in malaria's mice model of plasmodium berghei. ${ }^{22,23}$

$N$. sativa seed in ethnomedicine and in modern years for the cure of microbial diseases has been used without any known side-effects. Consequently, $N$. sativa can offer a precious medication for microbial ailments. ${ }^{24}$ However, supplementary research is needed to assess and discover the specific cellular and biomolecular mechanisms of the antimicrobial effects of TQ, only or in mixture with other drugs.

\section{ACKNOWLEDGEMENTS}

This project is supported by Al-Moalim MA Bin Ladin (MABL) chair for Scientific Miracles of Prophetic Medicine, College of Medicine, Taibah University, Saudi Arabia (research grant no. MABL 37/03).

\section{CONFLICT OF INTEREST}

Authors declare no conflict of interest.

\section{ABBREVIATION USED}

None.

\section{REFERENCES}

1. Proto WR, Coombs GH, Mottram JC. Cell death in parasitic protozoa: regulated or incidental? Nature Reviews Microbiology. 2013;11(1):58-66.

2. 2. Angel SO, Matrajt M, Echeverria PC. A review of recent patents on the protozoan parasite HSP90 as a drug target. Recent patents on biotechnology. 2013;7(1):2.

3. Baum M, de Castro EA, Pinto MC, et al. Molecular detection of the blood meal source of sand flies (Diptera: Psychodidae) in a transmission area of American cutaneous leishmaniasis, Paraná State, Brazil. Acta tropica. 2015;143(3):8-12.

4. Shanan S, Abd H, Bayoumi M, Saeed A, Sandström G. Prevalence of Protozoa Species in Drinking and Environmental Water Sources in Sudan. BioMed Research International. 2015;2015.

5. Vaerewijck M, Houf $K$. The role of free-living protozoa in protecting foodborne pathogens. Advances in Microbial Food Safety. 2014;2(5):81.

6. Haque SJ, Majumdar T, Barik S. Redox-Assisted Protein Folding Systems in Eukaryotic Parasites. Antioxidants \& Redox Signaling. 2012;17(4):674-83.

7. Ross AG, Olds GR, Cripps AW, Farrar JJ, McManus DP. Enteropathogens and chronic illness in returning travelers. New England Journal of Medicine. 2013;368(19):1817-25 
8. Verkerke HP, Sobuz SU, Petri Jr WA. Molecular diagnosis of infectious diarrhea: focus on enteric protozoa. Expert review of molecular diagnostics. 2014;14(8):935-46.

9. Brumlik MJ, Pandeswara S, Ludwig SM, Murthy K, Curiel TJ. Parasite mitogenactivated protein kinases as drug discovery targets to treat human protozoan pathogens. Journal of Signal Transduction. 2011;2011: Article ID 971968, 16 pages

10. Vermelho AB, Supuran CT, Cardoso V, et al. Leishmaniasis: Possible New Strategies for Treatment. 2014

11. Siddiqui MI, Usmanghani K. Comparison of allopathic and herbal medicine for the treatment of Entamoeba histolytica: A double blind clinical trial. Journal of Medicinal Plants Research. 2015;9(9):301-9.

12. Burits M, Bucar F. Antioxidant activity of Nigella sativa essential oil. Phytotherapy Research. 2000;14(5):323-8.

13. Ali BH, Blunden $\mathrm{G}$. Pharmacological and toxicological properties of Nigella sativa. Phytotherapy Research. 2003;17(4):299-305.

14. Zaoui A, Cherrah Y, Lacaille-Dubois MA, Settaf A, Amarouch H, Hassar M. Diuretic and hypotensive effects of Nigella sativa in the spontaneously hypertensive rat. Therapie. 2000;55(3):379-401.

15. Salem ML. Immunomodulatory and therapeutic properties of the Nigella sativa L. seed. International immunopharmacology. 2005;5(13):1749-70.

16. Moo-Puc R, Robledo D, Freile-Pelegrin Y. Evaluation of selected tropical seaweeds for In vitro anti-trichomonal activity. Journal of Ethnopharmacology. 2008;120(1):92-7.
17. Wink M. Medicinal plants: a source of anti-parasitic secondary metabolites. Molecules. 2012;17(11):12771-91.

18. Lenta B, Chouna J, Nkeng-Efouet P, Sewald N. Endiandric Acid Derivatives and Other Constituents of Plants from the Genera Beilschmiedia and Endiandra (Lauraceae). Biomolecules. 2015;5(2):910-42.

19. Khan AL, Hussain J, Hamayun M, et al. Secondary Metabolites from Inula britannica L. and Their Biological Activities. Molecules. 2010;15(3):1562-77.

20. Mohamed AM, Metwally NM, Mahmoud SS. Sativa seeds against Schistosoma mansoni different stages. Memórias do Instituto Oswaldo Cruz. 2005; 100(2):205-11.

21. Forouzanfar F, Bazzaz BSF, Hosseinzadeh H. Black cumin (Nigella sativa) and its constituent (thymoquinone): A review on antimicrobial effects. Iranian Journal of Basic Medical Sciences. 2014;17(12):929.

22. Mahmoud M, El-Abhar H, Saleh S. The effect of Nigella sativa oil against the liver damage induced by Schistosoma mansoni infection in mice. Journal of Ethnopharmacology. 2002;79(1):1-11.

23. Okeola VO, Adaramoye OA, Nneji CM, Falade CO, Farombi EO, Ademowo OG Antimalarial and antioxidant activities of methanolic extract of Nigella sativa seeds (black cumin) in mice infected with Plasmodium yoelli nigeriensis. Parasitology research. 2011;108(6):1507-12.

24. Emeka PM, Badger-Emeka LI, Eneh CM, Khan TM. Dietary supplementation of chloroquine with nigella sativa seed and oil extracts in the treatment of malaria induced in mice with plasmodium berghei. Pharmacognosy Magazine. 2014:10(Suppl 2):S357.

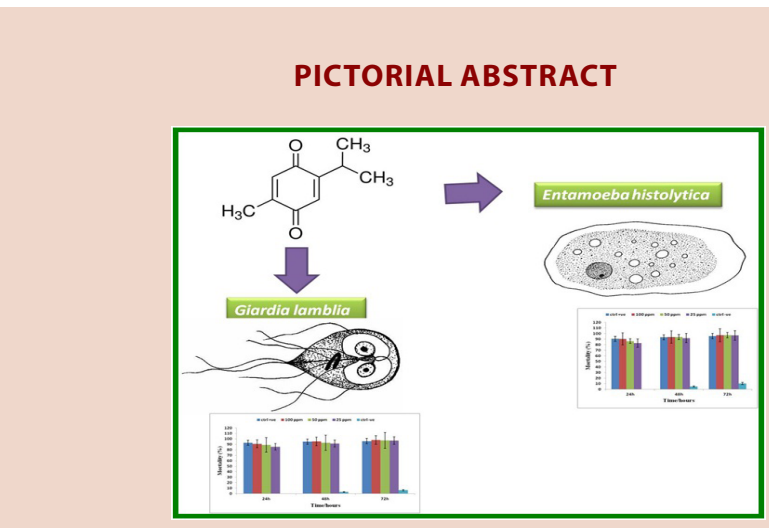

\section{SUMMARY}

- Thymoquinone (TQ) was tested against Entamoeba histolytica and Giardia lamblia using in vitro susceptibility assays.

- Results indicate that thymoquinone antiprotozoal properties.

- TQ is more potent on E. histolytica compared to G. lamblia.

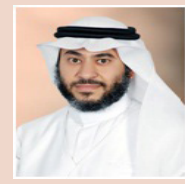

Professor Sheikh Is the first Saudi Neurosurgeon with double specialization holding both Microvascular and Endovascular qualifications. $\mathrm{He}$ is the head of Saudi Association of Neurological surgeons vascular/ Endovascular Section. He acted as the program director in several Saudi regions, latest in Madinah. He is the general director of several programs, including Mohamed BinLadin Chair for Scientific Research in Prophetic Medicine, the Hijama-Cupping center, and Madinah Neurosurgery Virtual Academy (MNVA LIVE). Prof Sheikh is known to be passionate for disseminating knowledge. He obtained Master degree in Medical Education from Maastricht University, and is presently a visiting professor of medical education in Takatsuki University, Japan. He is the founder of curriculum "Prophetic medicine" at Taibah University, and is of the founder group of the Pan Arab college of Neurosurgery. He initiated and runs a periodic Micro-surgical laboratory at Madinah. Of the several International responsibilities, he is the Saudi Second Delegate for World Federation of Neurological Surgeons: Member of World Federation of Neurological Surgeons Education and Training committee; the Saudi delegate for the European Society of Neurosurgery and member of its educational committee; and is editor and reviewer in several international and national scientific journals. During his academic career he has achieved 86 publications in international journals, book chapters, book reviews, and scientific reports. He was called upon as invited speaker, Chairperson, and presenter in more than 280 international symposia. Prof Sheikh is an inventor by nature having patented inventions that were appreciated nationally and globally by the reception of several golden awards. Prof Sheikh's ideas and innovations may be followed through his Web Site and YouTube Channel. 